\title{
Commentary: Innovate or perish in cardiac surgical training
}

\author{
Bobby Yanagawa, MD, PhD, ${ }^{\mathrm{a}}$ Tom C. Nguyen, MD, ${ }^{\mathrm{b}}$ David A. Latter, $\mathrm{MD},{ }^{\mathrm{a}}$ and \\ Michael A. Borger, MD, PhD \\ From the aivision of Cardiac Surgery, St Michael's Hospital, University of Toronto, Toronto, Ontario, Canada; \\ ${ }^{\mathrm{b}}$ Department of Cardiothoracic and Vascular Surgery, University of Texas Health Science Center and McGov- \\ ern Medical School, Houston, Tex; and ${ }^{\mathrm{C}}$ University Clinic of Cardiac Surgery, Leipzig Heart Center, Leipzig, \\ Germany. \\ Disclosures: Authors have nothing to disclose with regard to commercial support. \\ Received for publication Aug 9, 2019; accepted for publication Aug 12, 2019; available ahead of print Sept 30, \\ 2019. \\ Address for reprints: Bobby Yanagawa, MD, PhD, Division of Cardiac Surgery, University of Toronto, Division of \\ Cardiac Surgery, St Michael's Hospital, 30 Bond St, 8th Floor, Bond Wing, Toronto, ON M5B 1W8, Canada \\ (E-mail: yanagawab@smh.ca). \\ J Thorac Cardiovasc Surg 2020;159:590-1 \\ $0022-5223 / \$ 36.00$ \\ Copyright $(2019$ by The American Association for Thoracic Surgery \\ https://doi.org/10.1016/j.jtcvs.2019.08.022
}

In this issue of the Journal, Wick and colleagues ${ }^{1}$ describe contemporary challenges in attracting and training the best and brightest for cardiac surgery in Germany and the shift to a competency-based residency curriculum. This overview of the German experience is insightful. Understanding the strengths and weaknesses of other training programs inevitably provides personal insight into our own training paradigms.

The external pressures to cardiac surgical training are remarkably consistent to reports from North America, Europe, and Asia. ${ }^{2-4}$ The major challenges to recruitment represent a combination of (1) the perceived small pool of jobs, (2) low reimbursement, and (3) adequate "work-life balance." Attracting top-class medical students and more women to cardiac surgery is crucial to ensure the continued vitality of our specialty. There is a rough estimate of projected case load increase of $61 \%$ from 2010 to 2035 in the United States, with similar estimates worldwide. ${ }^{5}$ The pressures facing operative training include (1) lack of teaching cases as a result of a greater proportion of higher risk cases and emphasis on minimally invasive and transcatheter procedures, (2) residency work hour restrictions, (3) the need to obtain proficiency in wire skills, ${ }^{6}$ and (4) pressure on surgeons from publicly available outcomes reporting. In Germany, transcatheter aortic valve replacement has well surpassed surgical aortic valve replacement rates, well over half of mitral surgery is performed minimally invasively, and weekly work hour restriction is capped at an absolute maximum of 60 hours, although European work regulations restrict the work week to 48 hours. ${ }^{1}$

Germany has 79 cardiac surgery departments without a central residency selection process. A central process is efficient, because it requires fewer human resources, standardizes application packages, allows coordinated interview travel, and produces large-scale data for quality control

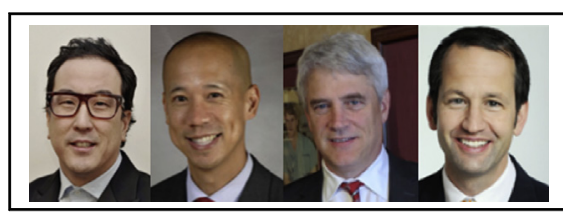

Left to right: Bobby Yanagawa, MD, $\mathrm{PhD}$, Tom $\mathrm{C}$ Nguyen, MD, David A. Latter, MD, and Michael A. Borger, MD, PhD

Central Message

Greater standardization and a shift to a competency-based residency curriculum should improve the consistency and quality of

See Article page 579 graduating surgeons in Germany.

monitoring and audit. According to the German Medical Chamber, roughly 50 to 70 surgeons complete their cardiac surgical training each year, which is relatively high for a country with a population of approximately 82 million (compared with 9 in Canada, population 37 million, and 90 in the United States, population 327 million). The comparatively high number of residents is partly a result of work hour restrictions and also the limited use of nurse practitioners and physician assistants in Germany.

Cardiac surgery training in Germany has been an integrated program for decades, whereas in Canada, all cardiac surgery was integrated in 1996, and in the United States, the first integrated cardiothoracic residents graduated in 2013. In 2018 , the German system underwent an overhaul to a competency-based, rather than time-based, curriculum model. The competencies include cognitive and methodologic, as well as experience and skill. Starting this year in Canada, advancement in cardiac surgery residency will also be competency-based, requiring successful completion of 54 discrete entrustable activities (eg, "performing surgery for mitral valve disease"). In the United States, the Accreditation Council for Graduate Medical Education has also transitioned to a hybrid time- and competencybased evaluation, with residents being required to meet specific milestones within several domains within a defined period of time. The overall goal is to allow learners to progress at their own pace, to provide regular structured feedback and coaching, and to identify problem candidates early in the training process with the goal of expedient, focused intervention. 
The move to greater standardization of the German cardiac surgical curriculum is a move in the right direction. The formulation of the new curriculum and didactic sessions hosted by the German Society for Thoracic and Cardiovascular Surgery is intended to achieve this. In Canada, the Royal College of Physicians and Surgeons of Canada oversees and certifies all 12 accredited cardiac surgery residency programs, as the Accreditation Council for Graduate Medical Education does in the United States. Given the variability in quality of teaching and the sporadic nature of some cardiac surgical cases, greater standardization will help to ensure that trainee education is as uniform and comprehensive as possible.

The move to a competency-based model is learner centric and should improve the consistency and quality of graduating surgeons, but only time will tell. For competencybased training to work, the criteria need to be clearly defined, unbiased, and nonpolitical. Ultimately, superstar trainees will become world-class surgeons despite, if not because of, our best intentions. There will also be individuals who are not suited to a career in heart surgery-not everyone that enters the astronaut training program becomes an astronaut - and it is our duty to identify and redirect these individuals early. There is third group of trainees who could go either way, and a trainee-focused program can help to ensure that many of these young doctors can realize their goal of becoming safe and competent heart surgeons.

\section{References}

1. Wick A, Beckmann A, Nemeth A, Conradi L, Schäfer A, Reichenspurner H, et al. Cardiac surgery residents training in Germany - status quo and future prospects. J Thorac Cardiovasc Surg. 2020:159:579-87.

2. Lebastchi AH, Tackett JJ, Argenziano M, Calhoon JH, Gasparri MG, Halkos ME, et al. First nationwide survey of US integrated 6-year cardiothoracic surgical residency program directors. J Thorac Cardiovasc Surg. 2014;148:408-15.e1.

3. Noly PE, Rubens FD, Ouzounian M, Quantz M, Shao-Hua W, Pelletier M, et al. Cardiac surgery training in Canada: current state and future perspectives. J Thorac Cardiovasc Surg. 2017;154:998-1005.

4. Park SJ, Kim DJ, Kim JB, Park KH, Lee JW. Cardiothoracic surgery training in South Korea: challenges and new hopes. J Thorac Cardiovasc Surg. 2020;159: 205-14.e1.

5. Moffatt-Bruce S, Crestanello J, Way DP, Williams TE Jr. Providing cardiothoracic services in 2035: signs of trouble ahead. J Thorac Cardiovasc Surg. 2018;155: 824-9.

6. Nguyen TC, Tang GHL, Nguyen S, Forcillo J, George I, Kaneko T, et al. The train has left: can surgeons still get a ticket to treat structural heart disease? J Thorac Cardiovasc Surg. 2019;157:2369-76.e2. 